\title{
The REM-theory: Implications for the study of large scale change
}

\author{
G. Goldman* \\ Department of Business Management, University of Johannesburg, \\ PO Box 524, Auckland Park Johannesburg 2006, Republic of South Africa \\ ggoldman@uj.ac.za
}

Received March 2011

\begin{abstract}
The University of Johannesburg (UJ) merger is typical of the transformation in South African Higher Education. This merger does not conform to the "norm", as it is ideologically motivated and thus the ideal base to study individual experiences of large scale change. Following a qualitative, grounded theory approach, 40 academic employees from UJ were interviewed. Findings indicate that academic staff relay their experiences and perceptions of the merger in three discernable time frames, each with its own dynamic. Collectively, these time-frames constitute the Reflective Experience of Mergers (REM) theory, which examines how merger experiences of academic staff shape their perceptions of and attitudes towards the merger over time. The REM- theory reiterates the temporal nature of change, its effect on the emotional and psychological wellbeing of individuals, and the role of leadership during a merger.
\end{abstract}

*To whom all correspondence should be addressed.

\section{Introduction}

Over the past two decades mergers have become a regular occurrence on managerial agendas as a strategic option (Papadakis, 2005; Panchal \& Cartwright, 2001). Their popularity is grounded among others in their apparent effectiveness as an adaptive response to an operating environment that is becoming increasingly competitive, integrated (global) and fast paced (Miller, 2004; Schabracq \& Cooper, 2000). Mergers are considered a quick and efficient means of enhancing growth (non-organic), improving synergy and economies of scale, diversifying and expanding into new markets, diluting and spreading risk (Papadakis, 2005); making them a means of considering sustainability in otherwise challenging operating circumstances.

Despite this generally optimistic view of mergers, there is substantial evidence to suggest that mergers and mergerrelated activities are not as successful as they were intended to be (Lundback \& Horte, 2005; Fulop, Protopsaltis, King, Allen, Hutchings \& Normand, 2005; Eriksson, 2004). Reported success rates for mergers are surprisingly low, and the incidence of failure reportedly varies between $40 \%$ and 80\% (Papadakis, 2005; Panchal \& Cartwright, 2001). The majority of mergers essentially fail to satisfy the original intention behind their initiation.

Mergers lead to operational re-organisation (cf. CIPD, 2000), which leads to disruptions in functional teams and confusion surrounding reporting lines, with people losing their "mental maps" of how the workplace functions (Fulop et al., 2005; Lundback \& Horte, 2005).
Any form of corporate combination has very real Human Resources (HR) implications (Papadakis, 2005; CIPD, 2000). Failing to address HR issues leads to consequences such as stress, fear, anxiety, depleted productivity levels, increased absenteeism, declining job satisfaction, resistance to change and a feeling of defeatism, (Fulop et al., 2005; Papadakis, 2005; Du Plessis, 2004; Eriksson \& Sundgren, 2004; Van Tonder, 2004) collectively referred to as "merger syndrome." However, there seems to be a trend to actively seek for areas where value will be added in a merger (Eriksson \& Sundgren, 2004; Schafer, 2004), to guard against demoralising staff and destroying knowledge capital (Cairncross, 2003; Collins \& Porras, 2000), and to actually create employment in a merger (Eriksson \& Sundgren, 2004; Ensor, 2003). This notwithstanding, there is still a general sentiment that HR-related issues are not receiving enough attention in a merger (Papadakis, 2005; Lessing \& Maritz, 2001; Lew-Kiedrowski, 2001).

The September 2000 Chartered Institute of Personnel and Development survey on the people implications of corporate combinations (CIPD, 2000), cites evidence to suggest that HR-related issues receive much attention during the merger planning and merger negotiation phase, but the importance of HR issues seems to dwindle during and after the merger process. This is, in part, due to the fact that most companies fully explore the legal and financial aspects of the merger, but often fail to consider thoroughly how the new organisation will be operated and managed after the deal. Therefore, successful implementation of a merger process is dependent on a sound merger plan that takes cognisance of not only financial objectives and strategic aspects, but also the organisational and cultural alignment, management style and expectations between organisations (Mitleton-Kelly, 
2006; McDonald, Coulthard \& Lange, 2005) which includes HR managment (Papadakis, 2005; Peterhoff, 2004).

The HR-related issues that emanate from corporate combinations are many and varied, and range from (Fulop et al., 2005; Peterhoff, 2004):

- Mechanistic issues, such as HR evaluation, organisational architecture and payroll;

- Issues to be negotiated, such as conditions of service and disciplinary code;

- Implementation approaches to integration; and

- "Soft" issues such as staff development, wellness and change management.

Of particular interest is the notion of change, as any corporate combination strategy implies change. With mergers - as a specific corporate combination strategy - the change is vast, as the whole essence of the organisation shifts. Schweiger, Csiszar and Napier (1993) contend that the major changes which often occur during merger implementation are: the elimination or shutting down of units that become redundant or that lack certain functions or activities; combination of units; and the creation of new interrelationships among units which never had to interact in the past. Just as people have different perceptions as far as the meaning of change is concerned, so too do they bring baggage along with them into a change arena (Eriksson, 2004; Pearse \& Amos, 2004). This in turn has the effect that people view change events as being personal, giving rise to their own expectations and interpretations of change (Pearse \& Amos, 2004; Rovio-Johansson, 2004; Van Tonder, 2004; Garratt, 2000). This can be potentially damaging to the successful roll-out of any change orientated intervention.

Notwithstanding the extensive existing body of literature on the topic following various theoretical perspectives, such as institutional, learning, evolutionary and agency theories (Beckman \& Haunschild, 2002; Ahuja \& Katila, 2001; Thornton, 2001), most studies have focused on the business world. In contrast, this study focuses on a higher education merger which, as we will see, deviates from the norm of mergers in the business world. The transformation of Higher Education in South Africa, which was initiated in 2002, brought to the fore a type of merger that was not grounded on economic or financial motivation. Higher education mergers were initiated solely on the basis of redressing imbalances of the past, which essentially makes them mergers based on ideological motives. These mergers are forced mergers and simply have to succeed; failure is not an option for the institutions involved.

This paper not only attempts to shed light on the new phenomenon of an ideologically motivated merger, but also attempts to integrate the lessons learnt from the study of ideological mergers, with merger literature in general, and in so doing, deepen our understanding of the complexities of mergers in general; specifically in terms of the experiences of those involved and affected by a merger.

\section{The research setting}

During the past four years some eight mergers of universities and technikons have taken place in the South African higher education sector. The reasons advanced by the South African government for the mergers in higher education, suggest that these mergers were politically and ideologically motivated (cf. Mokadi, 2002). The Higher Education environment was the setting in which Goldman (2008) undertook a study investigating how individuals and in particular academic staff - experienced a merger in higher education. This study aimed to gain a deeper and enriched understanding of academics' (as individual employees) experience of a merger and their subsequent commitment to it.

The paucity of literature on the individual experience of large scale change in general, and mergers in particular, further accentuates the need for research that seeks to fathom individual dynamics during such events. The value of the study, however, was further accentuated by the unique features of Higher Education mergers, which include the non-commercial origins of these mergers. This paper is an extension of the study by Goldman (2008), and aims to ascertain the implications of the REM-Theory to the study, and management, of mergers and large scale organisational change in general. The basic research question that is posed is:

\section{What does the REM-Theory contribute to the scientific study (as well as the management) of mergers?}

To answer the research question posed above, a conceptual debate is waged in this paper. Drawing from secondary data - and in particular previous research - the scientific and practical potential of the REM-Theory will be explored.

\section{Arriving at the rem-theory}

As previously detailed, this paper uses the study of Goldman (2008) as point of departure. This work was aimed at exploring the merger experiences of academic staff during the UJ merger; thus attempting to develop a framework of how individuals experience large-scale change, such as a merger.

\section{Research method employed}

The Goldman (2008) study was pursued from a qualitative, exploratory and interpretive point of view; which, as Mouton (1996) argues, attempts to gather new data and 'facts' and to establish whether there are interesting or novel patterns in the data. The choice of a qualitative design is generally considered appropriate when little previous research has been conducted in the subject domain (cf. Mouton, 1996). The qualitative approach was effected through a case study design, which allows investigation of phenomena as 'bounded systems' (Henning, Van Rensburg \& Smit, 2004); which are social entities demarcated (thus bounded) by parameters that enable exposure of their distinctive dynamics and from which data can be solicited. In Goldman's (2008) study, the focus was on change at a South African University, which can be viewed as a 
bounded system with clear parameters and a specific and unique dynamic.

The ontological platform for Goldman's study was indicated by the study's point of departure, namely the impact of a merger on people. It focused on the experience of individual academics and worked at the level of individual feelings, attitudes, beliefs, views, and understandings of the merger; the latter being personally and socially constructed and which fitted an interpretive research paradigm. In this regard, Neuman (2003) argues that researchers operating from within an interpretative paradigm strive to systematically analyse socially meaningful actions through direct observation, in order to understand how people create and maintain their social worlds. From an epistemological perspective it followed that first-hand accounts (e.g. verbatim narratives) of how the merger was experienced (obtained directly from those who experienced it), was most suited as a vehicle of knowledge.

The research population comprised all full-time academic personnel in the employ of the university in question. As with most qualitative studies, non-probability sampling was employed in this study - in particular as representativity in terms of the population, was not a consideration. However, for reasons such as the distinctly different nature and cultures of the merging institutions, variation in campus locations, differences in faculties, hierarchical levels and management philosophies, it was felt that the traditional approaches to sampling in qualitative studies be elaborated to allow for greater diversity in perceptions and experiences related to the merger. As a result, the sample size was structured on a purposive basis which would ensure participants from all faculties, across all campuses. This resulted in the selection of two research subjects per faculty per campus, except in those instances where the faculty has a presence of less than 10 full-time academic employees on any particular campus. In these instances sampling numbers were reduced to one research subject per faculty per campus. In this manner a sample of 40 research subjects was arrived at.

Open-ended, semi-structured interview techniques were used for data gathering (cf. Denzin \& Lincoln, 2005), which translated into an interview schedule consisting of three open-ended questions which prompted respondents to share their experiences, feelings, perceptions and expectations of the merger. A variation of Grounded Theory was employed as method of analysis to derive meaning from the gathered data. As all interviews were digitally recorded, they had to be transcribed whereafter the data was coded to facilitate categorisation and extraction of prominent themes, and ultimately theory building. Consistent with Corbin and Strauss' (1990) grounded theory approach, open, axial and selective coding was applied to surface themes from the data. During open coding, all sentences (the designated unit of analysis) were allocated labels. As a consequence every similar meaning phrase (sentence) received the same label, while every new meaning phrase was allocated a new label, and ultimately a series of themes emerged (Babbie \& Mouton, 2004; Henning et al., 2004). During axial coding, relations and linkages among these themes were revealed, while selective coding enabled the construction of an essential narrative (and theory) of the entire dataset as it pertained to the experience of the merger.

\section{Main outcome of the study}

Resultant from the analytical process, emergent themes were identified which afforded insights into academics' experiences of the merger and of the pre-merger phase. Through open and axial coding, data was reduced to 17 themes, with the first four being indicative of pre-merger experiences, the following nine proving insights into experiences of the implementation of the merger, and the latter four providing insights as to the predicted future of the merger (for a detailed expose of these 17 themes, kindly consult Goldman (2008)). These three time perspectives associated with the themes identified, represent different moments in the UJ merger, as experienced by academic staff of the University. These three perspectives can be drawn together in a theory which views the changes in merger experiences over time. One of the most salient features of this theory is its temporal nature, allowing changes in academics' experiences over time to surface more visibly.

This theory is referred to simply as the Reflective Experience of Mergers Theory, or REM-Theory. This integrated theory of academics' experience of a merger over time is depicted in Figure 1, and indicates the factors and variables that shape individual disposition in different phases of the merger. The REM-Theory views the time from the announcement of the merger, through the current point in time and into the future. The Past Perspective spans the time from merger announcement to the date that the merger takes effect, and comprises two discernable stages. Firstly, the emotive Reaction Stage depicts individuals' outlook and perceptions of the UJ merger directly after merger announcement, and comprises five variables:

- Non-acceptance of the reasons provided for the merger

- Fears and concerns associated with the merger

- Opportunities presented by the merger

- Personal outlook toward change

- Institutional predisposition

The second stage of the Past Perspective, the Preparation Stage, comes about over time as individuals enter into rational discourse concerning the merger. This stage is comprised of six variables:

- Initial contact with merging partners

- Concerns forthcoming from merger preparation

- Personal paradigms

- The merger planning process

- Politics

- The planning time frame afforded for the merger

The second perspective is the Current Perspective and spans the period from the date of the merger to the current point in time. During this Perspective, the attitudes of staff towards the merger are shaped by a complex interaction of four variables: 
- Perceptions of roll-out, (influenced by the role government, students and the community play in the merger).

- Perceptions of Management and Leadership have an impact on the individuals' perception of roll-out, but is also shaped by concerns resultant from roll-out.

- Roll-out of merger implementation is associated with concerns about the process.

- The feelings and emotions of staff permeate through this perspective and have a marked influence on the attitudes of staff towards the merger.
The Future Perspective investigates the expectations that individuals have toward the future of the merger. The expectations individuals hold about the future direction of the merger are indicative of their perceptions of future merger roll-out. The Future Perspective is shaped by three variables:

- Visions of the future for the institution

- Future expectations of management and leadership

- Workplace expectations (note that these workplace expectations are also impacted by the overall attitudes of staff (resultant from the Current Perspective)

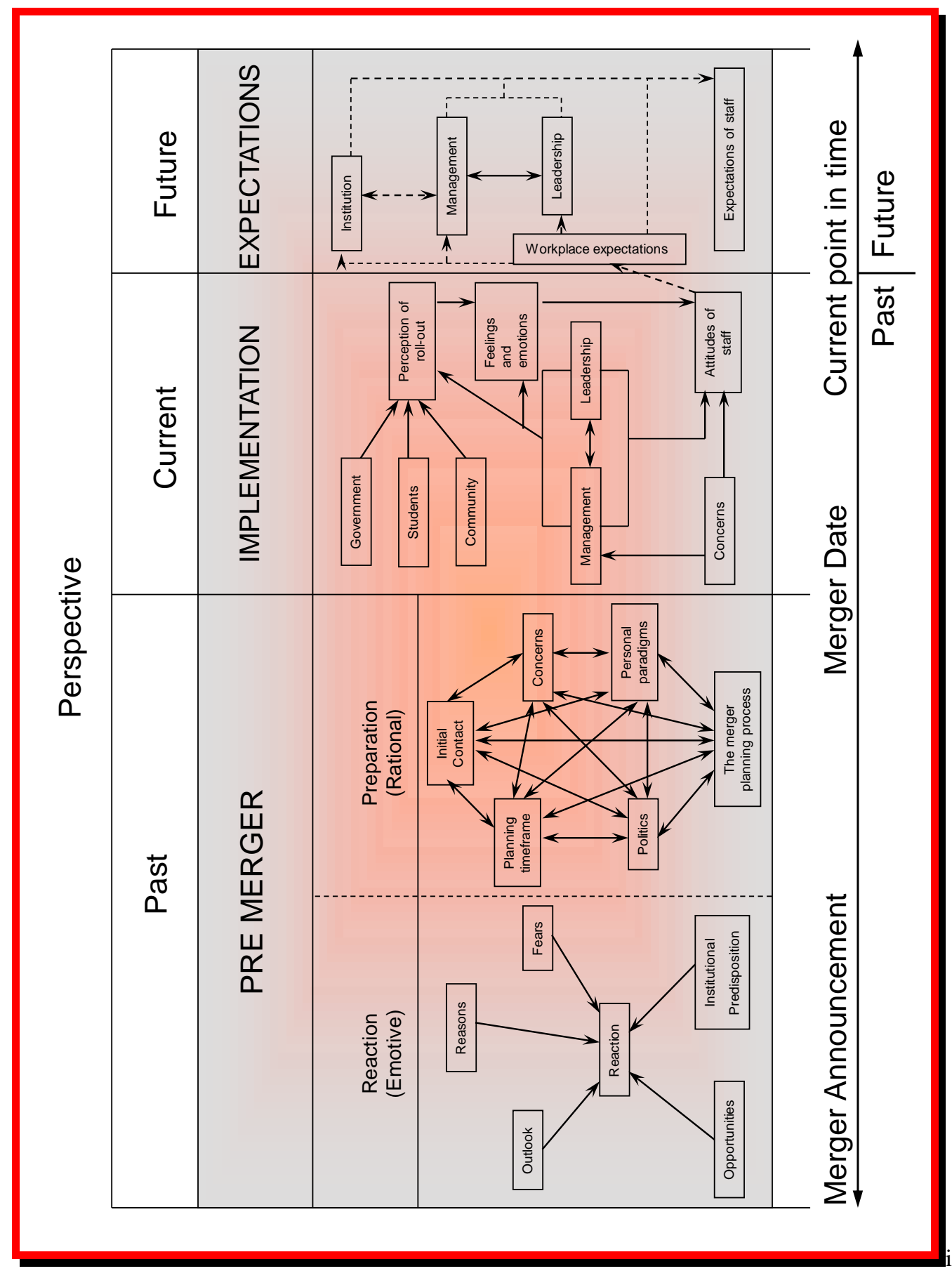

Figure 1: The reflective experience of mergers (REM) theory 
As the individual moves through these perspectives over time, emotive reaction gives way to more rational thought, familiarity with the merger environment, and eventually even demands in terms of future expectations. The disposition held by individuals in the past cannot be discarded; it plays a large role in shaping current attitudes, perceptions and outlook which, in turn, will have a profound effect on future expectations.

\section{What can the rem-theory offer?}

As ideological mergers have become a reality, as seen in South African Higher Education, the REM-Theory helps shed light on this unique and underdocumented type of merger. The REM-Theory also underpins certain fundamental people management issues concerning mergers in general, and furthermore acts as a call for more pragmatic research approaches to the study of management. In a nutshell, the following are the most salient points forthcoming from the REM-Theory:

- Uniquenesses of ideological mergers

- The importance of consultation

- Legitimate communication

- Management vs leadership in a merger

- Areas of managerial focus during a merger

- Pragmatic research approaches to management

These will now be expounded upon.

\section{Uniquenesses of ideological mergers}

The REM-Theory was borne out of the study of an ideological merger. As such, these mergers do not represent a conventional merger, as these mergers are not commercial in nature. This is an underdocumented niche of merger research, and one that necessitates further investigation, especially in the light of the currency of mergers between HEIs in South Africa. Existing HEI merger literature tends to be philosophical, reflective and speculative, with little empirical knowledge.

The study by Goldman (2008) indicates some important distinctions between ideologically driven and commercially driven mergers (although it did not set out to establish differences between ideological and commercial mergers). Firstly, it illustrates the pivotal role of government in mergers in Higher Education. Government had spelt out how the merger was to roll out, and that current capacity would be utilized, directly following the effective merger date as an interim measure until a permanent management structure was to be appointed. The merging partners, therefore, had little say in how the merger was to unfold. As the Government was the initiator of HEI mergers in South Africa and a large source of income for HEIs, it would stand to reason that it would also want to dictate how these mergers take effect.

Secondly, ideological mergers unfold at a much slower pace than commercial mergers do. Commercially driven mergers happen quickly; the objective is to bring the two entities together under a new banner and move on with business as quickly as possible. In so doing, uncertainty from staff, customers, suppliers and shareholders is reduced. This is not the case with ideological mergers. Indeed, in the case of the UJ merger, it took 14 months from effective merger date for a new top management structure to be appointed, constituting a so-called interim phase where current management capacity was utilised. This, however, was not unique to the UJ case. All mergers in Higher Education were typified by these interim phases which, in some cases, lasted up to two years. The temporal nature of the REM-Theory makes provision for the inclusion of such a phase over time. It does not mean that it is a pertinent variable that occupies a specific position within the model graphically, but rather that such a phase can be identified from a specific mix of variables from within the model, and specifically from within the Current Perspective.

\section{The importance of consultation}

Any large scale change - albeit a merger or otherwise implies (or at least should imply) lengthy, all encompassing (and often tedious) consultation. The challenge laid down to the managers is to create the correct mechanisms and forums for transparent, all inclusive and genuine process of consulting with all stakeholders, internal and external. This process of consultation should not only be harnessed to expedite the post change integration process, but also serve as a vehicle to foster commitment towards the outcome of any large scale change.

Although the consultative process of merger planning was both positively and negatively perceived by academics at UJ, negative perceptions hereof can do more harm than positive perceptions can add value. Seen as an essential element in creating buy-in into the UJ-idea and for inculcating an organisational disposition towards UJ, allinclusive and genuine consultation on the correct issues is sorely needed at UJ. This would necessitate innovative ways of consulting with all stakeholders. Although formal communications are deemed to be both successful and unsuccessful by academics, one has to admit that the negative sentiment uttered is cause to improve these efforts. The evidence suggests that there is a definite need for more focused, operational level communication, as well as more intensive communication.

\section{Legitimate communication}

The REM-Theory underscores the need for effective and frequent communication about the right things, especially focused towards internal stakeholders. The UJ merger illustrates the dangers of not communicating on the issues that staff wanted answers on. Although there were enough channels of communication, various media were employed, and the frequency of communication was adequate, the messages contained therein were not deemed useful for internal stakeholders. Thus, it created a breeding ground for rumours and an over-active grapevine, elements which are counterproductive to any formal communicative effort.

\section{Management vs leadership in a merger}

The REM-Theory underpins the distinction between management and leadership. Further to the long standing 
scientific debate surrounding the fundamental differences (or equality) between management and leadership, REMTheory points to these as two discernable, yet interrelated variables, and furthermore highlights and reiterates the importance of leadership effort in a merger, and therefore bolsters the call to make sure that, further to a sound merger plan, managers recognise that a merger is not merely dependent on their ability to manage the merger process, but also - and maybe more importantly - on their ability to lead staff members through difficult times of large-scale change.

Furthermore, the REM-Theory affirms the need for quick and decisive action during large-scale change, as a lack thereof manifests itself in frustrations and concerns raised by staff, which could negatively influence the way staff perceive the roll-out of the merger in general. Permanency, vision, direction, consistency, decisive and swift decision making, and firmness are managerial factors vital to the successful roll-out of large-scale change, such as a merger.

\section{Areas of managerial focus during a merger}

The REM-Theory firstly reiterates the fact that the principle of a merger is a concept that staff grapple to come to terms with, and when the motivation behind the merger is ideological, even more so. Many academics at UJ felt at odds with the reasons advanced for the merging of HEIs in South Africa, and specifically at their own academic institution. As these motives were basically ideologically grounded, academics felt that no rational or economic argument could be forwarded for the merger. Although there is acceptance of the merger, it is more of 'giving in' to the idea, rather that firm belief in the idea. Although the sentiment seems to be positive on the surface, there are still many reservations, and very few subjects are overtly of the opinion that they believe in the UJ. This is an area that necessitates the intervention of strong strategic leadership; as only a firm and decisive leadership corps can stimulate true buy-in to the idea of the UJ.

Also, the REM-Theory recognises that peoples' level of job satisfaction during a merger is influenced by the way they perceived the organisation they originally hailed from. The more favourable this institutional predisposition, the less favourable individuals tended to be to the idea of the UJ merger. Negative predisposition, for example, can override disagreement with reasons put forward to merge, as was the case with the UJ merger. As organisational predisposition is a product of entrenched attitudes, it is not something that disappears when a new institution, such as UJ, is born out of a merger. The challenge that managers are faced with, is to harness this organisational predisposition as point of departure to inculcate a favourable disposition amongst staff toward the merged institution.

Thirdly, merger roll-out at UJ has been viewed as slow and tedious, with many academics citing that mergers in industry are dealt with far more swiftly. Thus, academics at UJ felt that the transition was taking too long, which in turn fuelled more uncertainty and concerns about the future. It is thus imperative that managers realise that the quicker the change takes place, the better for all involved. A swift transition to a new status quo will largely negate uncertainty about the future, and allow staff to form new mental models of their new working environment..

Staff also undergo psychological discomfort during largescale change such as a merger, something that needs to be carefully monitored and managed. The more psychologically burdened staff become (albeit because of a phase of protracted uncertainty, or otherwise), the greater the potential for staff becoming genuinely dissatisfied in their working environments and with the change that has been imposed.

Lastly, fears and concerns will always abound as a result of large-scale change. Managers have an active part to play in addressing (especially) operational fears and concerns that staff experience. Operational concerns are manifestations of concerns relating to employees' work environment - their comfort zones, the place they feel safe at. Major upheaval and disruption of this working environment would typically evoke a range of responses, all stemming from psychological discomfort experienced as a result of the change at hand.

\section{Pragmatic research approaches to management}

This highly contextualised approach also calls for a paradigm shift within management and business scholars. A positivist research paradigm cannot accept findings of such a contextualized, intersubjective nature as valid. However, positivist research alone within the realm of business and management studies cannot provide all the answers. The biggest problem is that more positivist orientated approaches aim to generalise findings to an industry, geographic region or even an entire economy. However, more pragmatic, contextualised approaches appreciate the uniqueness of the organisation or business being studied. Uniqueness cannot be ignored, as it stands at the very essence of competitive advantage. There simply are no quick fixes and blanket approaches in the realm of business and management.

Development of the REM-Theory has reiterated the importance of the "insider" perspective, not only for purposes of meaningful interpretation of data, but also for gaining access to the research setting. In this case, Goldman did not achieve an "insider" status by "putting myself in their shoes". As an employee of the University, he is part of the setting. This, coupled with involvement with merger structures, proved invaluable in terms of access to interview subjects, as well as in establishing a rapport with interview subjects. This necessitates one to deduce that the application of qualitative methods will be very time consuming, laborious and slow in generating accurate data if the researcher is not part of the research setting.

\section{Taking the rem-theory forward}

As the REM-Theory was born from exploring the merger experiences of academics at the University of Johannesburg, it was never the intention to compare these experiences with the merger experiences of academics at other South African, or foreign universities. This study, therefore, presents ample opportunity for further research. 
If the REM-Theory is to be refined to a generic theory, the same methodology employed in this study must be applied to other mergers in higher education as soon as possible, before the process unfolds to such an extent that staff cannot readily reflect on their merger experiences. The REMTheory, although grounded in and most applicable to the University of Johannesburg merger, has been developed with the eye on future research to try and develop a generic framework to gain an understanding of individuals' experiences during a merger. Refinement of the REMTheory will have to be done through application at other HEIs and, in time, on other sectors and industries (it would be ideal to extend the REM-Theory to commercial mergers). The generation of a measuring instrument for application of this theory for purposes of hypothesis testing is also envisaged, as well as testing the theory as a whole through the use of Structural Equation Modeling.

It is envisaged that the REM-Theory would be able to define the variables contained therein at any point after the effective date of a merger by employing the same measuring instrument as employed in this study; either by means of personal interviews or by means of focus group interviews. Gathered data from the interviews can then be analysed with the use of the REM-Theory. This would involve several passes through the data, as would be the case when using the grounded theory approach of Strauss and Corbin (as used in this study). The application of the REM-Theory differs from this approach to grounded theory in that the analysis is lead by the REM-Theory itself.

During a first pass through the gathered data, the three perspectives of the REM-Theory would be discerned and data pertaining to each perspective grouped together. The idea is not to identify any variables pertaining to these perspectives, but to identify the three major time perspectives the REM-Theory is based upon. During a second pass through the gathered data, each perspective is closely scrutinised in turn. The variables identified under each perspective in the REM-Theory would then represent the categories the data has to be divided into. This is comparable to open coding according to Strauss and Corbin, however, the difference here is that this categorised coding follows the template laid down within each of the perspectives of the REM-Theory.

Once the underlying dimensions of the variables pertaining to each perspective have been identified, the REM-Theory now serves as a template to contextualise gathered data to a specific setting. A "picture" can now emerge of how staff members' disposition towards the merger is shaped during each perspective. The application of the REM-Theory cannot be seen as grounded theory, as it does not allow theory to emerge out of a specific setting, but rather presents a framework of how to interpret the data gathered from a specific setting. This approach could be described as being a more rigid approach to a priori qualitative content analysis; the inquirer is not given the liberty of constructing his or her own categories from literature, as the categories used against which to interpret the gathered data are dictated by the REM-Theory.
The use of the REM-Theory as a framework of analysis also suggests a quantitative aspect to the analysis of data gathered through the application of traditionally more qualitative data collection methods. This would typically apply where specific causal relationships identified in the REM-Theory are isolated and interrogated with the eye on (possible) statistical verification of these observed causal relationships.

As an exploratory study, this study has not only identified parameters of the merger experience and the leadership role in these merger experiences, but has also created a better understanding of individual merger experiences and the role leadership plays in these experiences. However, an exploratory study, per definition, cannot establish the magnitude or pervasiveness of the parameters of the merger experience. The latter should be the subject of future (comparative and more quantitative) studies that would be more explanatory and predictive.

Future research opportunities also lie within the content areas of the REM-Theory. As this study has reiterated and revealed, aspects such as institutional predisposition, personal visions, the perceptions of management and leadership during the merger, and the relationship that exists between these (and other) variables are central to the REMTheory. These variables and the relationships between them, as identified in the REM-Theory, create the opportunity for further, focused research on these variables and the relationships between them in the context of mergers. The scope that exists for further research and scientific investigation in the field of experiences of change are profuse, as most change-related literature focuses on structural, process and mechanistic aspects of organisational change.

\section{Concluding remarks}

To date, the extant literature appears to have directed scant attention to individual experiences of a merger, or any large scale change, for that matter. More detailed knowledge of how individuals experience change will enable business leaders to tailor change management interventions to negate the effect of these often overlooked human aspects of largescale change and facilitate more effective roll-out of change interventions.

\section{References}

Ahuja, G. \& Katila, R. 2001. 'Technological acquisitions and the innovation performance of acquiring firms', Strategic Management Journal, 22(3): 197-209.

Anstey, M. 2006. Managing change, negotiating conflict. Cape Town: Juta.

Babbie, E \& Mouton, J. 2004. The practice of social research. Cape Town: Oxford University Press.

Beckman, C. M. \& Haunschild, P. R. 2002. 'Network learning: The effects of partners' heterogeneity of experience on corporate acquisitions', Administrative Science Quarterly, 47(1): 92-124. 
Cairncross, F. 2003. The company of the future: Meeting the management challenges of the communication revolution. London: Profile Books.

CIPD (Chartered Institute of Personnel and Development). 2000. Survey report: People implications of mergers and acquisitions, joint ventures and divestments. September 2000. London: CIPD.

Collins, J.C. \& Porras, J.I. 2000. Built to last: Successful habits of visionary companies. London: Random House.

Corbin, J. \& Strauss, A. 1990. 'Grounded Theory research: Procedures, canons, and evaluative criteria', Qualitative Sociology, 13(1): 3-21.

Denzin, N.K., \& Lincoln, Y.S. 2005. The Sage handbook of qualitative research. Thousand Oaks: Sage.

Du Plessis, A.J. 2004. 'Conflict during the changing process: HR's role in 2002 and 2010'. In Proceedings of the $7^{\text {th }}$ IFSAM (International Federation of Scholarly Associations of Management) World Conference held in Goteburg, Sweden; July 2004.

Ensor, L. 2003. 'Commission challenges job losses report: Mergers have resulted in job creation', Business Day, 30 September 2003, p.4.

Eriksson, P.E. 2004. 'Barriers to change: Implementation of partnering in the Swedish construction industry'. In Proceedings of the $7^{\text {th }}$ IFSAM (International Federation of Scholarly Associations of Management) World Conference held in Goteburg, Sweden; July 2004.

Eriksson, M. \& Sundgren, M. 2004. 'Managing change: Strategy of serendipity? Reflections from the merger of Astra and Zeneca.' In Proceedings of the $7^{\text {th }}$ IFSAM (International Federation of Scholarly Associations of Management) World Conference held in Goteburg Goteburg, Sweden; July 2004.

Fulop, N., Protopsaltis, G., King, A., Allen, P., Hutchings, A. \& Normand, C. 2005. 'Changing organisations: A study of the context and processes of mergers of health care providers in England', Social Science and Medicine, 60:119130.

Garrat, B. 2000. The learning organisation: Developing democracy at work. London: Harper-Collins.

Goldman, G.A. 2008. 'Academics experience of a merger in higher education'. D Phil Thesis, University of Johannesburg: Johannesburg.

Henning, E.; Van Rensburg, W. \& Smit, B. 2004. Finding your way in qualitative research. Cape Town: Van Schaik.

Lessing, N. \& Maritz, G. 2001. 'Juxtapositions in management: Critical issues to be resolved', Management Today, 17(1):10-14.
Lew-Kiedrowski, V. 2001. 'Change masters to see companies through modern challenges', Management Today, 17(2):22-23.

Lundback, M. \& Horte, S.A. 2005. 'Decision making in conditions of constant change - a case within the automotive industry', Management Decision, 43(2): 220-235.

McDonald, J., Coulthard, M. \& Lange, P. D. 2005. 'Planning for a successful merger or acquisition: Lessons from an Australian study', Journal of Global Business and Technology, 1(2): 1 - 11 .

Miller, D. 2004. 'Building sustainable change capability', Industrial and Commercial Training, 36(1): 9-12.

Mitleton-Kelly, E. 2006. 'Coevolutionary integration: The co-creation of a new organizational form following a merger and acquisition', Emergence: Complexity \& Organization, 8(2): $36-47$.

Mokadi, C.C. 2002. Transcript of dinner address held on 31 July 2002 at an informational dinner to discuss the Technikon Witwatersrand's perspectives on the merger proposals of the Ministry of Education. Undistributed document.

Mouton, J. 1996. Understanding social research. Pretoria: Van Schaik Publishers.

Neuman, W.L. 2003. Social research methods: Qualitative and quantitative approaches. Boston: Allyn \& Bacon.

Panchal, S. \& Cartwright, S. 2001. 'Group differences postmerger stress', Journal of Managerial Psychology, 16(6): 424-433.

Papadakis, V.M. 2005. 'The role of broader context and the communication program in merger and acquisition implementation success', Management Decision, 43(5): 236-255

Pearse, N.J. \& Amos, L. 2004. 'Understanding the employees' experience of organisational change and the role of an organisational vision', Commercium, 5(1): 1-9.

Peterhoff, D. 2004. Designing HR due diligence in the context of mergers and acquisitions'. In Proceedings of the $7^{\text {th }}$ IFSAM (International Federation of Scholarly Associations of Management) World Conference 2004 held in Goteburg, Sweden; July 2004.

Rovio-Johansson, A. 2004. 'Contextualised meanings of integration in mergers'. In Proceedings of the $7^{\text {th }}$ IFSAM (International Federation of Scholarly Associations of Management) World Conference held in Goteburg, Sweden; July 2004.

Schabracq, M.J. \& Cooper, C.L. 2000. 'The changing nature of work and stress', Journal of Managerial Psychology, 15(3): 227-241. 
Schafer, L. 2004. 'Is the honeymoon over? Looking at the marriage of SAS and Marketmax', SAScom, $4^{\text {th }}$ Quarter 2004: 48-49.

Schweiger, D. M., Csiszar, E. N. \& Napier, N. K. 1993. 'Implementing international mergers and acquisitions', Human Resource Planning, 16(1): 53-70.

Shin, S.J. 2003. 'Facilitating inclusive identity: HR practices, perceived fairness and intergroup cognitions in corporate mergers'. Unpublished PhD thesis, Texas A\&M University

Strauss, A. \& Corbin, J. 1990. Basics of qualitative research: Grounded theory procedures and techniques. Newbury Park: Sage.

Thornton, P. H. 2001. 'Personal versus market logics of control: A historically contingent theory of the risk of acquisition', Organization Science, 12(3): 294-311.

Van Tonder, C.L. 2004. Organisational change: Theory and practice. Pretoria: Van Schaik. 